\title{
Compare of physical structure and content of counselling between consultation services and psychotherapy government agencies and the private sector in Kurdistan province
}

\author{
Sharmin Rahmani ${ }^{1, a}$, Mahmoud Goodarzi *2,b \\ ${ }^{1}$ Masters of clinical psychology, Department of psychology, Islamic azad university, Science and \\ Research branch, Sanandaj, Iran
}

$2^{*}$ Professor base 7, Ph. D of family therapy, Department of psychology, Islamic azad university, Sanandaj, Iran

åRahmanysharmin9@gmail.com 'bg.sauc@gmail.com'

Keywords: physical structure; content of counselling; counseling; psychotheraps.

Abstract

The purpose of this study was compare the physical structur an ntent o counselling between consultation services and psychotherapy government ag ncies an e pr vate sector in Kurdistan province. The research is descriptive and comparative study pop ction included all psychotherapy and counseling centers in Kurdistan. therefo amo. the population of through available sampling a total of 16 centers selected and do ware collo ysing a questionnaire quality services of Jafari with the reliability of 0.83 a d a correlation coefficient of (Cronbach's alpha $=0.76$ ). The results of analysis of independen $\mathrm{T}$ test shoy'ed that, between the physical structure consultation and psychotherapy government a ncies and the private sector in Kurdistan province there is a significant difference but cantent of c 11. g and psychotherapy government agencies and the private sector in Kurdistan pr there is no significant difference. This means that quality of physical structure was higher in $p$ vate so however in terms of content there is no difference between two centers.

\section{Introduction}

Human life is ever-changi g, all - mpassing. The speed of economic and social changes constantly adds to the co $1 \mathrm{p}$, ity and ris of the living conditions of the population and the degree of insecurity, uncertain and tration leads so that the person to resolve their issues have to get help from resource oecomes avan $\%$ Unfortunately ask for help from other sources is not always successful [1]. $O$ e of $t$ main reasons for the lack of awareness and understanding of the fit and proper help and a nce, of vithdrawals from their unjust [2]. This is where the need for centers to provide cientih dvice on the correct. In these centers, counselors, therapists and social worker pro a var of services such as career counseling, family, health, education [3] and addis to eln peope learn to live a more balanced and more successful [4] and choices appropria in amment areas of his life more fun out [5]. They move people in a positive and productive arn to their potential for adaptation and socialization of power [6] and uses and with changes in the perceptions, and with new insights and gain new life in a positive direction to life [7]. Because client satisfaction due to population growth and existing crisis happen each course is changing the awareness of the needs and determine the services necessary to achieve the objectives seem [8]. Astalard (1996) believes that the role and use of client satisfaction as an important component in assessment services, and considers the result of the improving knows [9]. People expect the centers with lower costs, taking into account their satisfaction and fairness in providing consultative services and receive appropriate services. The government is also desirable to ensure service quality, service and distribution service providing financial access for poor people to follow [10]. Giving a variety of client satisfaction evaluation counseling centers in Iran has been abroad. Mohammadi (2007) to evaluate the effectiveness and efficiency of counseling and psychological counseling centers pay education. Methods of descriptive statistics and practical. The main findings 
were that the clients of the quality of service and performance consultants are satisfied centers to solve problems [11]. Dortaj, Hussein, the Taliban and compelling 1389 study of veterans satisfaction of medical services provided by the Foundation conducted a martyr and Veterans Affairs and veterans of the services provided to the conclusion that satisfaction is moderate [12]. Felix Rodriguez (2003) in Washington, America's annual survey of client satisfaction with the quality of substance abuse treatment services performed. In this study, patients with similar levels of satisfaction were reported by public and private sectors [13]. Bchamps and Byalynk and Chuck (2002) America during his research came to the conclusion that the satisfaction of private and public institutions alike, and no significant difference was found in this area [14]. Apart from the private sector in counseling and psychotherapy service provider organizations, government agencies as well as most of the clients are very important. In addition, because the private sectornnsulting environments are different from those of government agencies and such factors co ald pos. y be the difference between the characteristics of the services provided. This study oht to con are the two institutions in terms of clients are satisfied.

\section{Research Methodology}

Due to the nature of the present study, investigate is descripti e and a varati e. The study population include all psychotherapy and counseling centers ir distan in $/$ (a total of 30 Consultation Center government and 18 units private) that th cit according to sprawl on the basis of geographical location at the provincial level, (t) Qorveh and Sanandaj) were selected. Then between the public and prival centers, counseling and psychotherapy in these cities the sample were equal sel tion and questionnaire was conducted.

\section{Tools of data collection}

The collect data to assess the quality of consu tiny consionnaire quality of consulting.

This questionnaire by Jafari and colleagues (20 3/ wery made and came into force in Iran. The questionnaire was designed to asse verify professors fan is located. In the initial phase questionnaire to 10 patients in pr ate at public stitutions. The questionnaire bugs such words and phrases that are inaudible $p$ tro correct. To determine reliability and test - retest (TEST - RE TEST), a que sionnair th 24 questions (12 out of every group of government agencies and private clie vere comp within two weeks Pearson correlation coefficient in public centers $(\mathrm{r}=\% 8$. and rivate centers $(\mathrm{r}=\%$ 85), respectively. The correlation coefficient of the questionnaire wow calculat wy Cronbach's alpha of \% 76 and internal correlation coefficient (Cronbach's alph $=0.7$ has been, eported. This form of 46 questions divided into three categories depending on $h$ h as fo ned the first class of the individual information such as age, sex, education and ser and sked for the second opinion researcher on the (physical structure, applians s, sultins. "ality consulting, including consulting) puts into question any of these cases ed o the 4 op ons next 5 (very good, good, bad, very bad) to answer is given in response to quest $m$ of model (Very Good. good. bad. very bad) was performed slopes leading scores in e. area is between 5 to 20 and scores of each area on the 3rd floor weak (grades 5 to 10), intermed (grades 10 to 15) and good grades (15 to 20) division and then of quality after picking up scores of four areas mentioned in the poor category (20 to 40) average (40 to 60) and good (60 to 80$)$ were classified

\section{Method analysis the data}

The descriptive analysis of data from deviation criterion and tables descriptive and inferential analysis to study data and research questions using T-test for independent groups was used for all the assumptions. In order to answer the questions of descriptive and inferential statistical analyzes were performed using SPSS 22 software. 


\section{Findings}

Table 1. Descriptive inform (Average studied Agencies government and private sectors)

\begin{tabular}{|c|c|c|c|}
\hline Agencies government & abundance & groups & Average \\
\cline { 2 - 4 } and private sector & Government & 8 & $\% 50$ \\
\cline { 2 - 4 } & private & 8 & $\% 50$ \\
\hline Total & 16 & 16 & $\% 100$ \\
\hline
\end{tabular}

Table 1 show that 8 centers were selected among governmental centers $(\% 50)$ and 8 centers were selected among private Centers (\%50).

\section{The inferential data}

1. Are the quality of physical structure between consultation servic and choth apy government agencies and the private sector different?

Table 2. Results of t-test variance analysis quality of physical stry vre veen co ultation services and psychotherapy government agencies an the priva

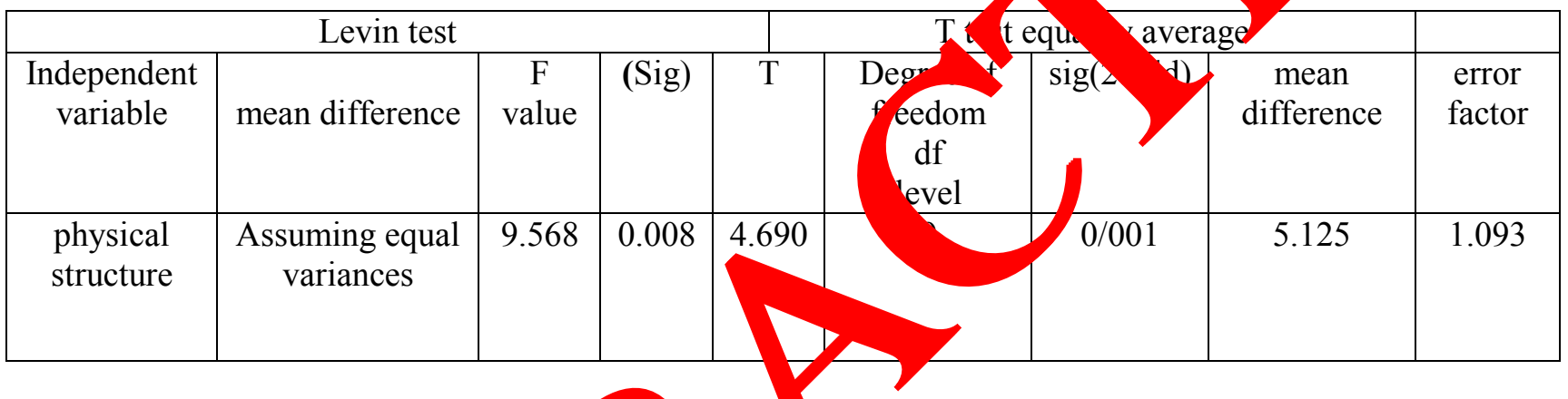

To compare the analysis qu ity of physica structure between consultation services and psychotherapy government age cic ate sector and T-test for independent samples was used. The results obtained $s^{\prime}$ owed tha 9.568$)$ of the smaller table is not so significant. The $t$ test assuming equal variance $\mathrm{Na}$ ed. The $\mathrm{t}$ obtained with $\mathrm{t}=0.001 \mathrm{df}=9$ degrees of freedom and significance level (0.0. repo a larger table $\mathrm{t} p \leq 0 / 001$. Therefore, it was concluded that between physical s uoure betwo onsultation services and psychotherapy government agencies and the private s ctor th is a sigy ificant difference.

2. Are the qua of con nt of counselling between consultation services and psychotherapy governm ncies the private sector different?

Tabla

Services and psychotherapy government agencies and the private sector
\begin{tabular}{|c|c|c|c|c|c|c|c|c|}
\hline $\begin{array}{c}\text { Levin test } \\
\text { variable } \\
\text { difference } \\
\text { value }\end{array}$ & $\begin{array}{c}\text { mean } \\
\text { valent }\end{array}$ & (Sig) & $\mathrm{T}$ & $\begin{array}{c}\text { Degree of } \\
\text { freedom } \\
\mathrm{df} \\
\text { level }\end{array}$ & sig(2taild) & $\begin{array}{c}\text { mean } \\
\text { difference }\end{array}$ & $\begin{array}{c}\text { error } \\
\text { factor }\end{array}$ \\
\hline $\begin{array}{c}\text { content of } \\
\text { counselling }\end{array}$ & $\begin{array}{c}\text { Assuming } \\
\text { equal } \\
\text { variances }\end{array}$ & 3.394 & 0.087 & 0.472 & 14 & 0.644 & 0.500 & 1.059 \\
\hline
\end{tabular}

To quality of content of counselling between consultation services and psychotherapy government agencies and the private sector and T-test for independent samples was used. The 
results obtained showed that $\mathrm{F}$ (3.394) of the smaller table is not so significant. The $\mathrm{t}$ test assuming equal variance was used. The t-test obtained with $\mathrm{t}=0.644 ; \mathrm{df}=14$ degrees of freedom and significance level $(0.01)$ reported a smaller table $\mathrm{t} p \geq 0.001$. Therefore, it was concluded that between the quality of content of counselling consultation services and psychotherapy government agencies and the private sector there is no significant difference.

\section{Discussion}

According to the results in Table 2, quality of physical structure between public and private centers statistically significant difference. The results for this hypothesis with research Parvizi and colleagues (2003) and parsley and colleagues (2008) [1, 15]. After considering the results of public centers and private authorities if they want their clients to be satisfied with the quam of the components and the quality of their physical facilities in focus., the high level of atisfactio vith the physical characteristics of auxiliary equipment in this study seem logical to pu centers 6]. People towards them increases. When you walk into a room let the room $m y$ arfect $\mathrm{c}$. Some ames when you get into the room, you feel relaxed and comfortable. Sometime it is p sible nter the room you like some clinics and health centers that give an unpleasant te, o you. linough the physical space of counseling centers have problems, but shall have ne aiscip that ne references comfort [17] every workshop can be a picture of his personalit on individ ,ehavior reflects his inner personality. That with what facilities we provide sp e for ir cliento is important. The decoration and arrangement of parts and consumables ro very i rrant And when talking about in terms of consultation with the authorities shou' not sit behind a desk. Retaining the table and between the counselor and the gap. Seat counselo and have a form, a type and a color. When authorities specify where to sit if he will be most comf ble. The obunselor and the front seats are better but is slightly angled with sufficient space betwe hem the client feels his privacy has been invaded. On location consultant is alway lable in me room should be a Napkin until the cry of these napkins clients save them from unn ress arbances [3]. Consulting room location should be chosen where the authorities hear soun outsiae the room and not afraid to be heard by others. Better consultation process b. $\mathrm{O}_{\mathrm{a}}$ people n the phone or not cut unnecessarily.

According to the results in 7 , 3 , he qualit of content of counselling between consultation services and psychotherapy difference. The results ob aned for hypothesis with research Jafari (2008) are consistent [18]. This category incly es quality ords of clients and the integrity of it. In this section, the Interview, diagnosis un grven referral, and follow-up should be identified. In general, this section should is y itten in a way / comprehensive and far from any unnecessary verbiage and brevity that Ac rding the results of all these, in public and private institutions are equally respected. It sho con dered that the new consulting activity and the lack of detailed knowledge their ties, nakes the expectation of reduced services and those with the least resourc sare nvince d satisfied.

\section{Conclu}

Results owed that, between of quality of physical structure consultation and psychotherapy government agencies and the private sector in Kurdistan province there is a significant difference. But content of counselling and psychotherapy government agencies and the private sector in Kurdistan province there is no significant difference. This means that quality of physical structure was higher in private sector. So government agencies to provide better and more efficient services to clients should make greater efforts to improve the physical space advice. However in terms of content there is no difference between two centers. There for according to the consultants, private institutions of government are working today can claim proof of the accuracy of the content quality of the advice is the same in both centers. 


\section{References}

[1] Shafiabadi, A, Counseling and psychotherapy, Tehran academic, Roshd, Tehran, 2012.

[2] Pakgohar, Mino, Rahimi, F. and M. Abbas. Check the quality of family planning counseling provided to patients in health centers affiliated to Tehran University of Medical Sciences Research, (2000), 63-71.

[3] Windy, Dryden, Counseling in a nutshell, First ed. Danjeh, Tehran, 2009.

[4] Taheri, N., Fereydooni, M., Cheraghian, B., Khezni, Sabrie, Assess patients' satisfaction with the quality of services provided in health centers of Abadan and Khorramshahr, Journal of nursing and midwifery, 2010, 8 (4), $204-211$.

[5] Judith, A., Lowis, Robert, Dana, Gregory, Blevins, substance abuse counseling: an individualized approach, the second, Roshd, Tehran, 2012.

[6] Hoseinian, Simin, Basic of Counseling Psychology, Roshad, Tehran, 2011.

[7] Shechtman, Zipora, group counseling and psychotherapy with children and ac scents, A aye noor, Tehran, (2007).

[8] Navabinejad, G, Tips and group counseling, the study and developm nt of 'uman Books, The publisher, Centre for Research and Human Development. Foa tion (IAF W ashington DC, 2012, $19-25$, www.lwilbun/phf.org.

[9] Tavakoli, Mahdokht, Evaluation of satisfaction with the qua of the so centers in the city of Torbat junior high. Journal, 2007, 40-60.

[10] Leshli Parsa, Kheir Khah, A survey of patients' satisf tun of q ity of social services and police centers. Tehran University: Departmen of Social So aces, Monthly human development police, 2010, 8 (39).

[11] Mohammadi, SH, influenced. Examine the eff iveness an efficiency of mental health services and counseling centers, counseling and vcholo, acal services. New ministry of Education and Research psychology, 200 5) 73-90.

[12] Hosseini, Sarah; Dortaj, Fariborz and the Altu Mahdi, Veterans satisfaction of medical services provided by the Foundation marty Jurn - Veteran medical research -the second year, 2008. Fifth edition.

[13] Rodriguez, F, client speak oy Was hgton st $/$ department of social health services, division of alkhol and abuse, Aval ab h

[14] Bechamps, M, Bialek, P, Prrvatı on and Public Health, Public Health. Tehran, 2002.

[15] Parvizi, D., Rahgoz , Vamegh , Vaml influencing client satisfaction in public centers and comparison th the ivate adkiction treatment centers Kurdistan. Journal Hakim, 2003, 48-53.

[16] Nelson, Jor L, Rio ard, Intro action to counseling skills, treat and activities, 2ed, Roshd, Tehran, 2

[17] Rafiei. H, A sment of satisfaction in clients of family counseling centers in Tehran. Up ve of 12 Welfare and Rehabilitation Sciences 2001; 102. and Rehabilitation

[18] Jan atami Zad, Nikta, Compare satisfaction clients from public and private out patie habilitation centers in Kurdistan, University of Medical Sciences and Physiotherapy: Group in nagement and rehabilitation, Journal of rehabilitation, 2008, 9 (3) (4), 35 - 36. 